$$
\text { جماليات الثظم الزخرفية للأبواب الشعبية في المملكة العربية السعودية }
$$

Aesthetics of Decorative Systems for Popular Doors in Saudi Arabia as a Source of Art Appreciation in the Light of the Standards of the Specialized Framework

\author{
إعداد \\ د/ محمد بن سعيد العنزي \\ الباحث: بكلبة التربية ـ قسم التربية الفنية
}

$$
\begin{aligned}
& \text { الفصل الدر اسي الثاني } \\
& \text { 0) } \varepsilon \varepsilon 1 / / \varepsilon \varepsilon \text {. }
\end{aligned}
$$





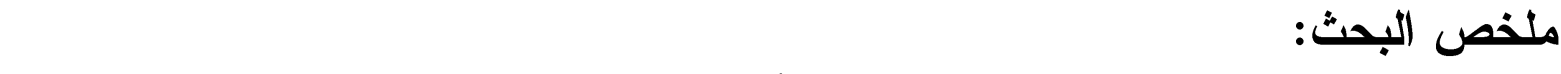
هدف البحث إلى التعرف على جماليات النظم الزخرفية للأبو اب الثعبية في المملكة العربية السعودية، وتحديد اهم معايير التذوق الفني المتضمنة في الإطار التخصصي لهجال التربية الفنية

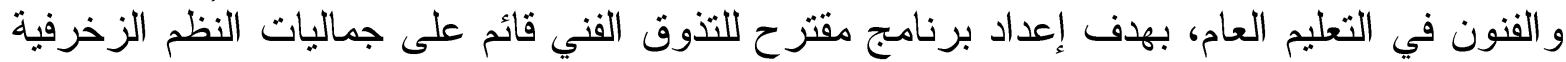

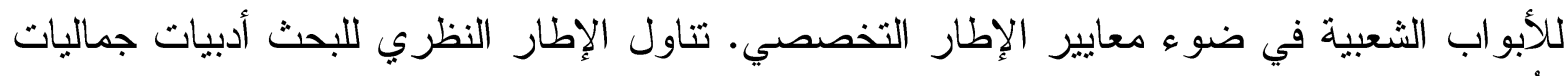

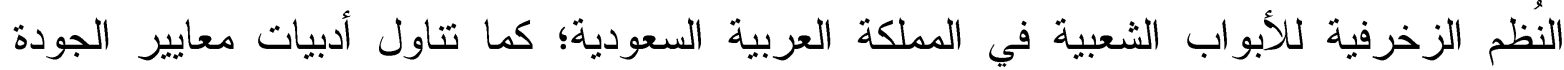

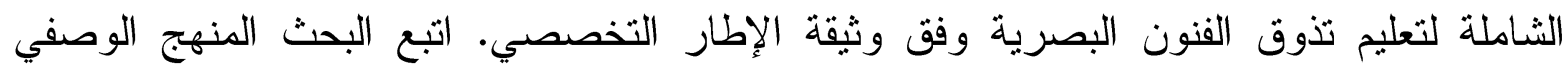

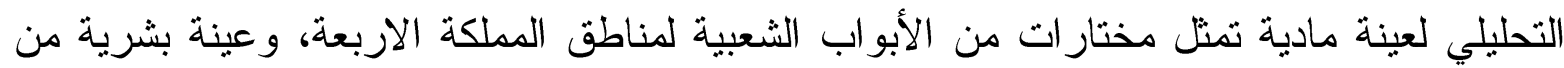

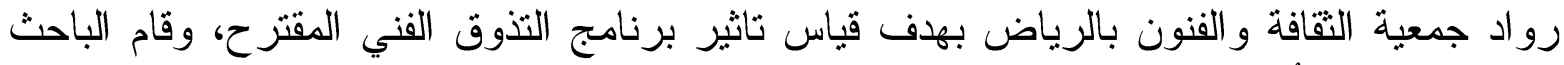

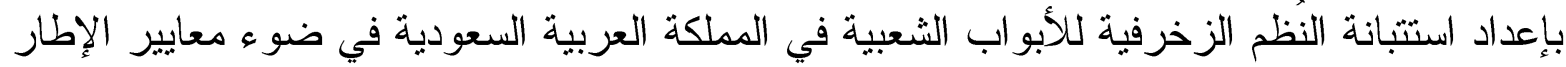

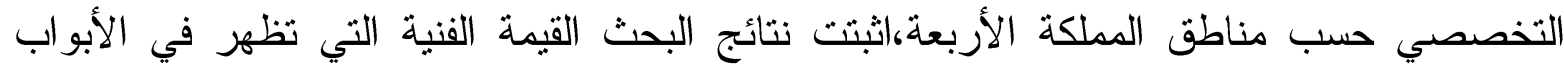

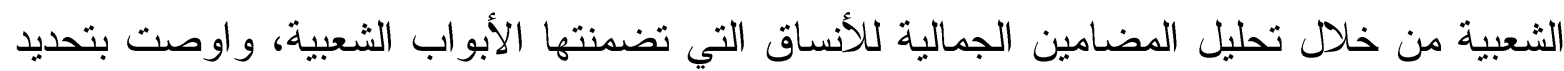

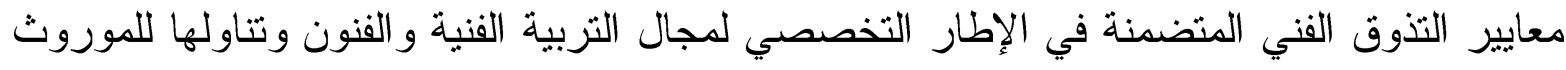
في المملكة العربية السعودية. الكلمات المفتاحية: النظم الزخرفية، الأبواب الثعبية في السعودية، معايير الإطار التخصصي.

\section{Search Summary:}

The aim of the research is to identify the aesthetics of the decorative systems of the popular doors in Saudi Arabia, and to identify the most important standards of artistic taste included in the specialized framework of artistic education and the arts in general education, with the aim of preparing a proposed program for artistic taste based on the aesthetics of the decorative systems of the popular doors in light of the standards of the specialized framework. The theoretical framework of research dealt with the aesthetics of the decorative systems of popular doors in Saudi Arabia, as well as the literature of the overall quality standards for teaching the taste of visual arts according to the document of the specialized framework. The research followed the descriptive analytical method of a physical sample representing a selection of popular sections of the four regions of the Kingdom, and a human sample of the pioneers of the Association of Culture and Arts in Riyadh in order to measure the impact of the proposed artistic tasting program, The researcher prepared the questionnaire of the decorative systems of the popular doors in Saudi Arabia in light of the criteria of the specialized framework according to the four regions of the Kingdom, the results of the research proved the artistic value that appears in the popular sections by analyzing the aesthetic contents of the patterns contained in the popular sections, and recommended the identification of the standards of artistic taste included in the specialized framework of the field of artistic education and arts and its handling of the heritage in The Kingdom of Saudi Arabia.

Keywords: Decorative systems, popular doors in Saudi Arabia, specialized framework standards. 
يعتبر التذوق الفني أحد دعائم البنية النقافية للمتعلم، وهي علم له الفكر الفلسفي والمنطقي الذي يعد اتجاهًا معرفيًا وتعبيريًا، يعبر عن المفهوم التطبيقي للتربية الفنية من خلال شقين، الأول: "خاص بالمعرفة ويشمل المحتوى وهي العلمي لمادة التربية الفنية، و الآخر : خاص بالقيمة يكون لها عائد على الفرد و المجتمع من خلال ما تقدمه من در اسات

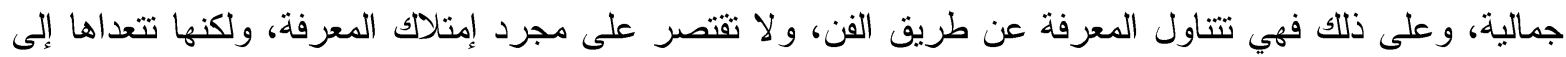
الخبرة بالقوة التعبيرية، و القيمة الكامنة في محتوى الفن، وبدون هذا المفهوم تصبح التربية الفنية مادة لا معنى لها"

. (V乏)

وفي ظل الثورة المعرفية، و التطور الهائل الي يشهده العالم في مجال تعليم وتعلم الفنون البصرية، "قد أصبح من الصعوبة على الطالب استيعاب هذا الكم الهائل من المعلومات واستغلاله بالأساليب التقليدية القديمة، مما يحتم وضع معايير و أسس تربوية تساعد في تطوير المناهج الدراسية التي يتلقاها طلاب التربية الفنية والفنون ما يعزز

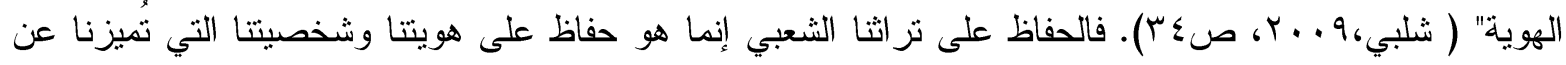
غيرنا " ويبدو أن أهمية تعزيز التراث لاى الطلبة و التققيف به هو أحد الأساليب الهامة في المحافظة على الهوية

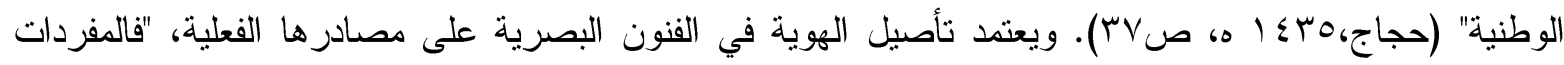
الزخرفية ومكملات العمارة الثعبية مجال يسهم في تحديد الهوية الثقافية للمجتمعات وتاريخها، فمجالات العمارة عبارة عن تشكيل وظيفي إلى جانب كونها تشكيل اجتماعي، تخضع لمؤثرات إجتماعية و إقتصادية، إضافة إلى "خضو عها لعو امل متعددة تنكل طر از ونسق هذه الزخارف. (John,2003,p62) ويمنل التزاث الثعبي مصدر من مصادر الموروث التشكيلي الذي يجدر الحفاظ عليه، ودراسة وتحليل مكوناته الجمالية ليكون مصدراً خصباً لدارسي الفن لاستلهام موضوعاتهم الفنية. فالمجتمعات الجديرة بالبقاء تحافظ

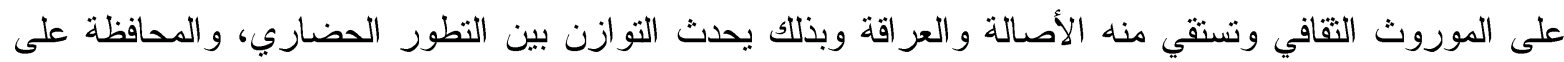

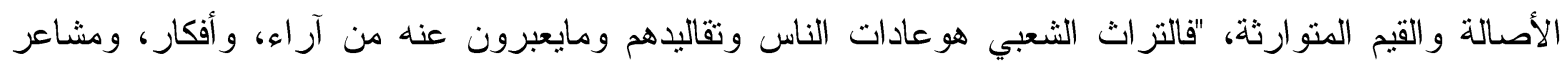

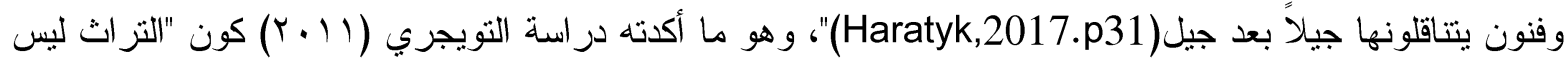
هو الماضي بكل ما حفل به من تطورات، وما شهده من أحداث تعاقبت عبر العصور، ولكنه الحاضر بكل تحو لاته

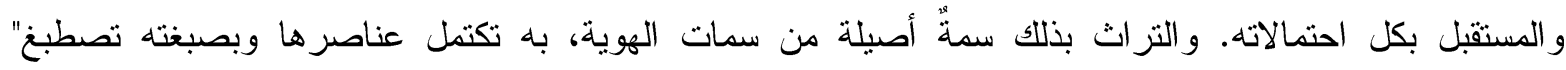
( ( )

ونظراً لما تتمتع به المملكة العربية السعودية من مساحة شاسعة وتتوع في المناطق واختلاف التضاريس

و الإمكانات البيئية التي أدت إلى إختلاف في المظاهر الإجتماعية، والعادات والتقاليد، وفنون الزخارف التهاف المعمارية بكافة أنشكالها حيث أن "المو اقع التراثية في المملكة نتوعت حسب نوع البيئة الجغر افية والمناخية للبلاد؛ فالمملكة بلد منز امي الأطر اف متتوع التضاريس فهناك المناطق المنبسطة والجبلية إلى جانب وجود بيئات صحر اوية وأخرى ساحلية، إضافة إلى وجود عدد من المناطق الحضرية التي اتسمت معالمها التزاثية بامتز اجها مع الحضارات العابل العربية و الإسلامية المجاورة "(التزاث العمر اني في المملكة، • ( • ب، صس (1). ويعتبر تدريس مقررات التذوق الفني لجماليات النظّم الزخرفية للأبواب الثعبية أحد تطبيقات تعليم الفنون في ضوء معايير الإطار التخصصي، وحتى يتحقق في هذه المقررات الكفاءة والفعالية المتوقعة منها، لابد أن تصمم محتو اها وفق معايير إسترانيجية محددة، تسند إلى مجموعة إنى 
من المعايير، ومن أبرزها معايير تخص المتعلمين المستهدفين وخصائصهم، ومعايير تخص الأهداف التعليمية

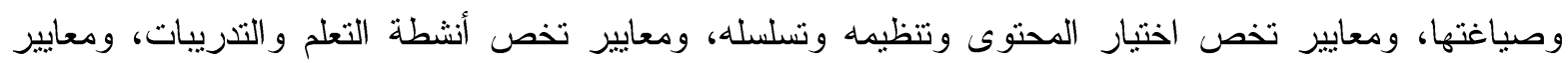
تخص نوع التغذية الر اجعة، ومعايير تخص تقويم التعليم. مشكلة البحث: أصبح لبرامج التزبية الفنية دوراً معاصراً من خلال التأكيد على التراث الثعبي للمملكة مع خلال الانفتاح

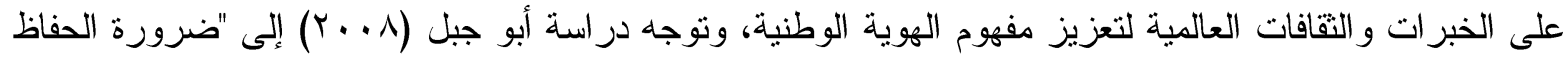
على الموروث الثقافي من خلال التعبير الفني، على اعتبار أن الفن الثعبي بالمملكة من الموروثات التي لاز الت في

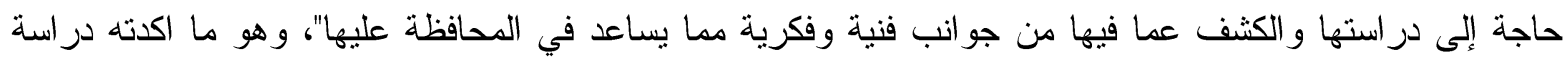

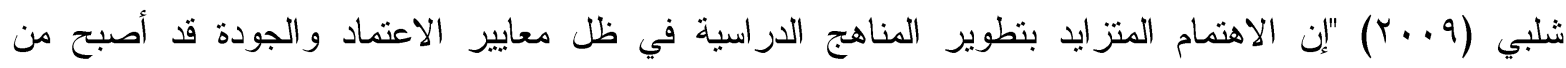
الضرورة الحتمية التي يجب أن يكون لنا دوراً في النهوض بها، وربطها بالاحتياجات التتموية لدفع عجلة التقدم وخدمة أغراض التتمية، لتتعكس إيجابًا على مخرجات التذوق الفني وتسخيرها لتحسين عملية التعليم في مقررات التربية الفنية وجودتها في ضوء معايير الجودة الثاملة وفق وثثقة الإطار التخصصي لمجال التربية الفنية في التعليم العام في المملكة العربية السعودية، وتحدد تعريفه ونطاق تعلمه، وأهدافه، وبنيته، وكيفية تضمين الأبعاد المشتركة فيه، و المبادئ التوجيهية لبناء معايير التزبية الفنية للمستويات و الصفوف الدراسية، حيث تستتد هذه الوثيقة إلى وثائق الإطار الوطني المرجعي لمعايير مناهج التعليم العام في المملكة العربية السعودية، و التوجهات التربوية المضنة في أبرز الوثائق و البحوث العلمية الحديثة في تعلم وتعليم التزبية الفنية، ونم إعداد هذه الوثيقة بخبر ات وطنية؛ لتوجه بناء معايير التربية الفنية وتتفيذها عبر المستويات و الصفوف الدراسية، وتنترك هذه الوثيقة مع غيرها هن من وثائق الأطر التخصصية لمجالات التعلم الأخرى في تحقيق رؤية معايير مناهج التعليم في المملكة العربية السعودية، و الوفاء

بمتطلبات رؤية المملكة . ب. r. r. (1) ما جماليات النظم الزخرفية للأبواب الثعبية في المملكة العربية السعودية؟ لمانه (Y) ما اهم معايير التذوق الفني لإطار التخصصي لمجال التربية الفنية والفنون في المملكة العربية السعودية؟ (Y) ما إمكانية إعداد برنامج مقترح للتذوق الفني قائم على جماليات النظم الزخرفية للأبواب الثعبية في المملكة

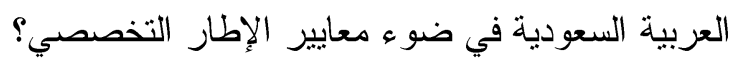
أهد اف البحث: (1) التعرف على جماليات النظم الزخرفية للأبواب الثعبية في المملكة العربية السعودية. (Y) تحديد اهم معايير التذوق الفني المتضمنة في الإطار التخصصي لمجال التربية الفنية والفنون في التعليم العام في المملكة العربية السعودية. (r) إعداد برنامج مقتزح للتذوق الفني قائم على جماليات النظم الزخرفية للأبواب الثعبية في المملكة العربية السعودية في ضوء معايير الإطار التخصصي. أهمية البحث:

( (1) التأكيد على الإعتز از والانتماء الوطني من خلال المحافظة على تراث المملكة الوطني و التعريف بالموروث الذي يعتمد على المضامين الجمالية الأبو اب الشعبية السعودية. 
(r) تقديم رؤى فنية معاصرة للتذوق الفني قائمة على عناصر التراث المادي للأبواب الثعبية كدخل التواصل

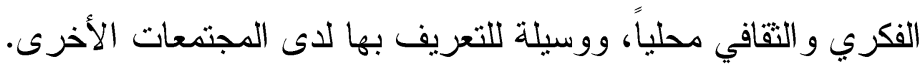
(ץ) توثيق عناصر الأبواب الشعبية في المملكة العربية السعودية، والتعرف على تصاميمها، وزخارفها وسماتها المحلية كأحد العناصر الأساسية في التكوين المعماري للعمارة التقليدية. (؛) إعادة قراءة التزراث للكثف عن مضامين، وعلاقات وتتظيمات تجمع بين الأصالة والمعاصرة من خلال إبراز المضامين الجمالية للأبو اب الثعبية بالمملكة العربية السعودية.

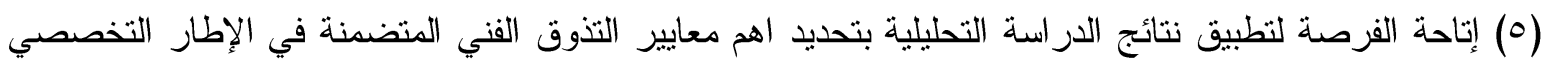
لمجال التربية الفنية و الفنون في التعليم العام في المملكة. حدود البحث: الحدود الموضوعية: جماليات النظم الزخرفية للأبواب الثعبية في المملكة العربية السعودية في ضوء معايير الإطار التخصصي " برنامج مقترح للتنوق الفني". الحدود المكانية: الدناطق الجغرافية في المملكة العربية السعودية تبعاً للأقاليم (المنطقة الوسطى، المنطقة الثرقية، المنطقة الغربية، المنطقة الجنوبية).

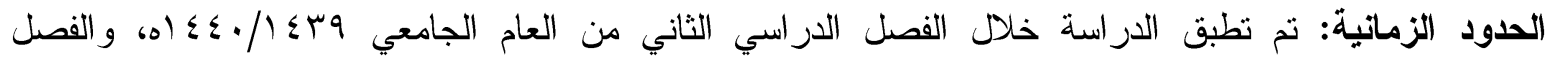

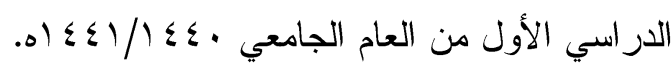

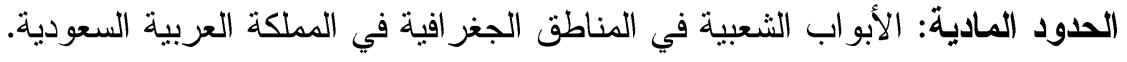

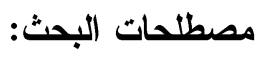

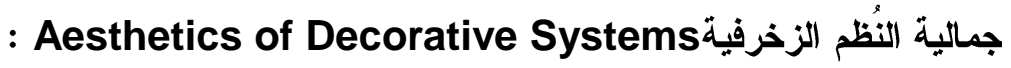
الجمالية: "الجمال هو وحدة العلاقات الثكلية بين الأثياء التي تدركها حو اسنا" "2018,p29ert) .(Longman,2018,p29)" التعريف الإجر ائي: هي عدد من الدلالات والمعاني التي تظهر في مجموعة من العلاقات الداخلية بين النظم الثكلية

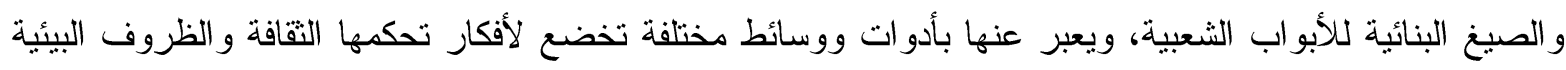

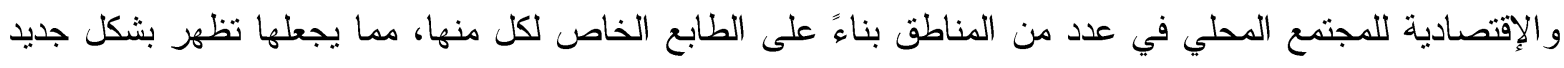

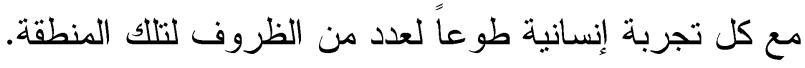

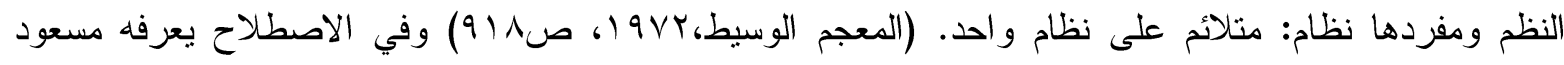

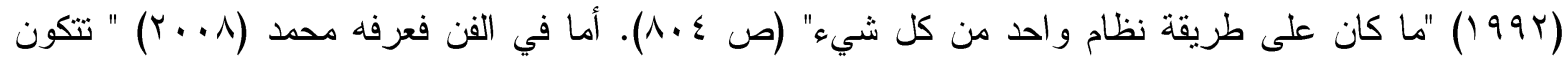

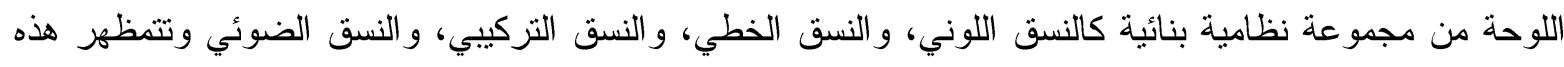

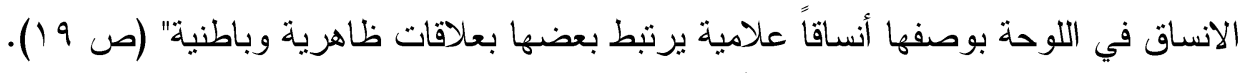

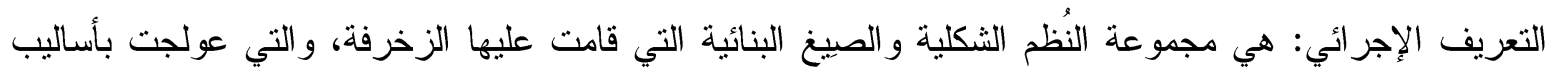

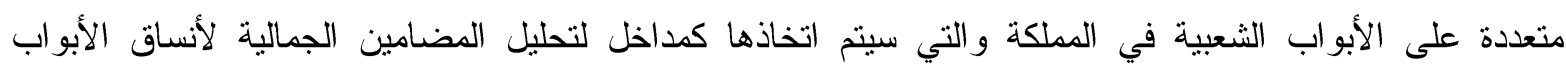




\section{الأبواب الثعبية Popular Doors}

الأبواب: ومفردها باب، وجمعها أَبو اب، بيبان، إصطلاحاً"هو المدخل، وماتسد به فتحته من خشب ونحوه وهو المدخل

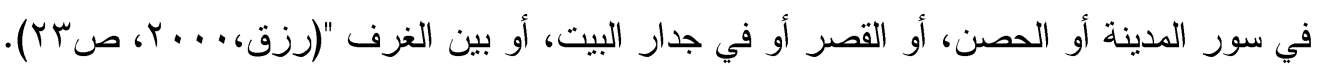

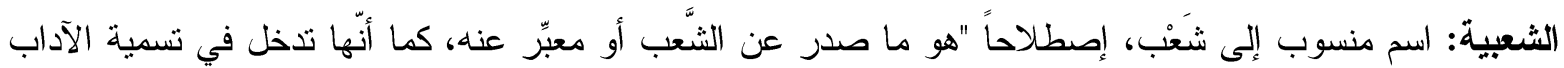

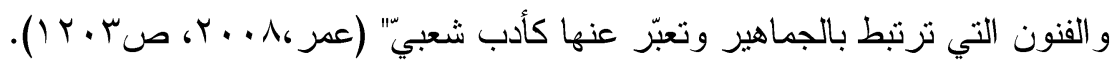
التعريف الإجر ائي: كل ما تم تتفيذه على الأبو اب الثعبية بإختلاف خاماتها، وتعدد أساليب وتقنيات معالجتها بغرض وناب

تجميلها وتزينها، وذللك في كلٍ من (المنطقة الوسطى، المنطقة الثرقية، المنطقة الغربية، المنطقة الجنوبية).

التذوق الفني Apt Apreciation:

المعني الاصطلاحي: هي مصدر تذوَّقَ الأشكال الفنية. فالذائقة التشكيلية هي الخبرة الجمالية ومعيار التذوق و الاستجابة للأعمال التشكيلية كقيمة جمالية من الجانب التشكيلي و التقني وتختلف اللغة النشكيلية والرموز البصرية التكنيك وطريقة التناول نتيجة اختلاف الحس الجمالي، والانفعالات ومعرفية وتميز بين القيم البنائية والمحتوى

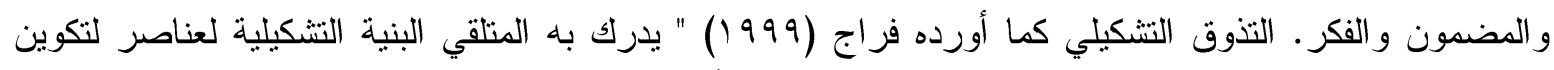

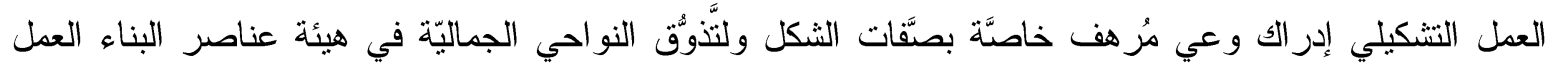

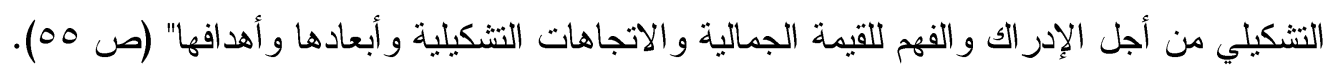
تعرف الدراسة التذوق التشكيلي اجر ائياً: بأنه معيار الاستجابة الثعورية، وعملية التذوق و الاستجابة الجمالية للأعمال التشكيلية كقيمة جمالية. التي تنكل المنطلق الفكري لطلاب التربية الفنية المرحلة الجامعية، بخطوات منهجية للتقيف التشكيلي للمفاهيم الجمالية المرتبطة بالإبداع. الار اسـات السابقة:

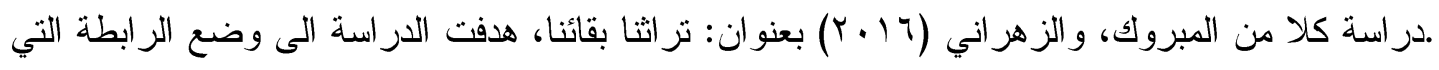

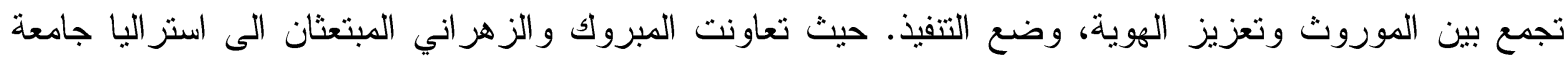

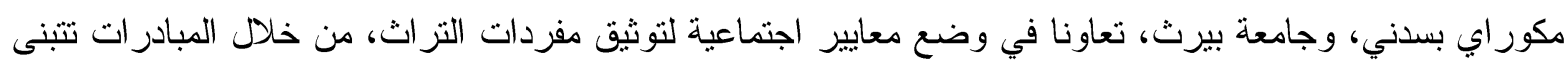
الهيئة العامة للسياحة والآثار عدداً الحرفية تستهدف بها فئئات عمرية معينة هم طالب وطالبات المرحلة الابتدائية، وذلك من خلال تتفيذ عدد من النشاطات التي تتظمها بالتعاون مع وزارة التربية والتعليم وجمعيات غير ربحية كجمعية يهدف إلى التسبيق رعاية الطفل. وتتبنى دراسة المبروك و الزهراني العلمية مشروعاً بين وزارة التربية و التعليم و الهيئة العامة للسياحة والآثار النتاج جيل جديد فني وحرفي، يركز على الطراز المعماري القديم، وذللك بتتبع ما يجري في المدارس فيما يتعلق بتنفيذ بعض النشاطات، وورش العمل التى نزكز على جانب التراث المعماري.

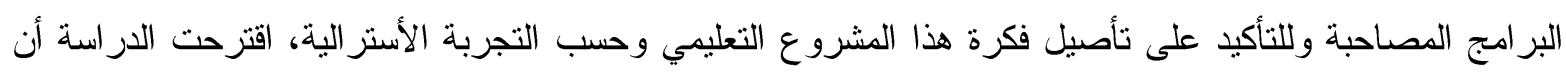

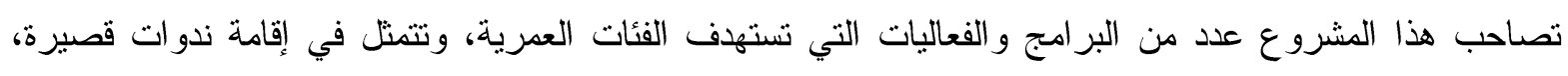
وعروض مسرحية، وحلقات حوار، وورش عمل للأطفال دون سن العانشة، يتم ترشيحهم من قبل عدد من المدارس

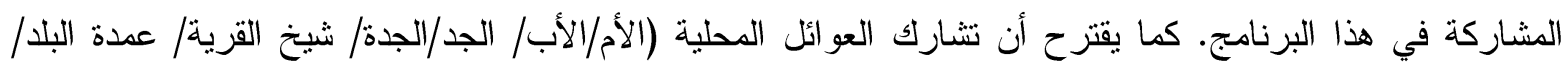
رجال كبار في السن) ممن يمتلكون بعض من هذا الموروث الحضاري في الندوات وورش العمل. الأمر الذي يساهم برسم صورة واضحة للتر ابط بين الجيلين القديم والحديث. وأن التراث يمر الآن بمرحلة العبور المنسق للجيل القادم. 


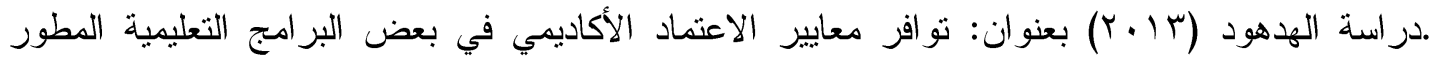
بنظام الويدز (wids) بكلية التزبية الأساسية في ضوء بعض المتغيرات هدفت الدراسة إلى تعرف مدى نو افر معايير الاعتماد الأكاديمي في البرامج الأكاديمية التخصصية (التربية الفنية) المطورة في كلية التربية الأساسية من خلا لهل معايير نظام الويدز، وتحديد الاختلاف في مدى تو افر هذه المعايير، وتعرف وجود فروق ذات دلالة إحصائية بين متوسطات درجات عينة الدراسة ومتغيرات الدراسة (الخبرة، التخصص، الدرجة العلمية)، فيما يرتبط بمدى تو افر هذه المعايير• ومن أجل تحقيق أهداف الدراسة صممت إستبانة (مقياس) من ثمانية محاور • تشنمل على (هو) فقرة،

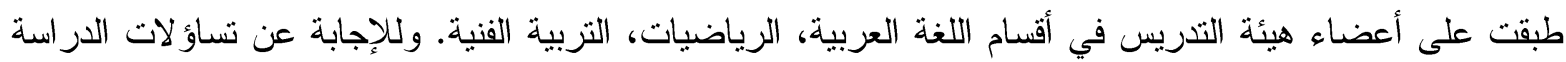
تم استخراج التكرارات، النسبة المئوية، المنوسطات الحسابية، الانحرافات المعيارية، اختبار "ف" تحليل التباين الأحادي.، واختبار "تtest المرتبطة بتطبيق نظام إعداد المعلم وبمجالاته، وتتو افق مع الخطط الدر اسية واستر اتيجياتها. وتعطي الأهداف توصيف المقررات ومفاهيمه الأساسية، وتركز على مهارات المواد العلمية اللازمة للإعداد بطرق تدريسية مختلفة ومتتوعة. و أظهرت النتائج قصورا في كفايات المقررات بالنسبة للأبعاد الاجتماعية الخاصة بالمجتمع المحلي وتر اثه، و افتقار المقررات الدر اسية لعو امل الإبداع و المنافسة و التكامل مع المقررات الأخرى. وأوضحت النتائج أن متغيرات الدر استة (الخبرة، التخصص، الدرجة العلمية) ليس لها تأثير في استجابات عينة الدراسة، حيث لا يوجد فروق دالة والة إحصائيا بين منوسطات درجات العينة. وفي ضوء النتائج توصي الدراسة بنشر نقافة الجودة والاعتماد الأكاديمي، و الإفادة من مقياس الدر اسة وتطبيقه على البرامج الأكاديمية الأخرى في الكلية.

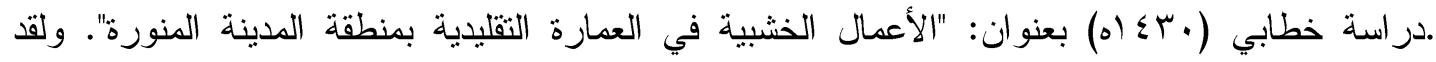
استخدمت الدراسة المنهج الوصفي التحليلي في وصف للوحدات الزخرفية، أشكالها، أنو اعها وطرق تتفيذها، و استخدمت المنهج المقارن من خلال عقد مقارنات بين الوحدات الزخرفية الخشبية وتحديد أوجه الثبه بين أنماطها

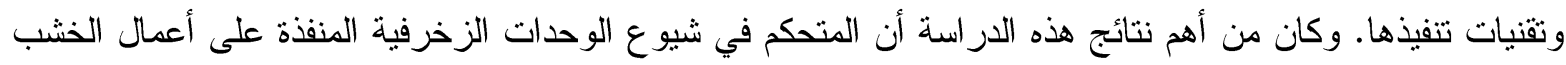
الثابتة هو الذوق التقليدي المحلي السائد والناتج عن الانصهار الثقافي المتعدد الذي أعطى الطابع المحلي في النسق العام للعادات و التقاليد. ولقد افادت الدراسة الحالية في التعرف على التحليل الفني للوحدات الزخرفية، ومعرفة

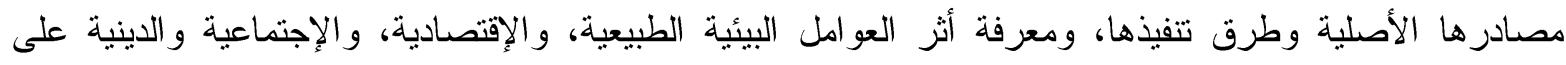

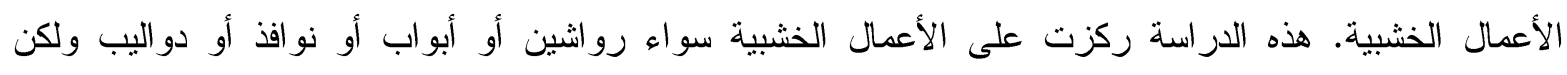
الدراسة الحالية سوف تركز فقط على الوحدات الزخرفية على الأبواب الخشبية، سماتها وخصائصها الفنية، طرق تنفيذها و الإستفادة منها في استحداث مداخل وصياغات تثكيلية للطباعة.

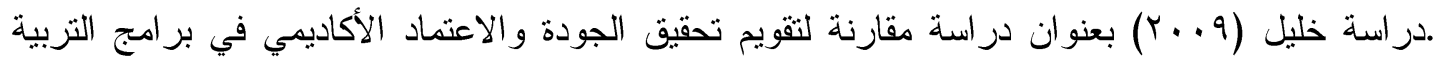

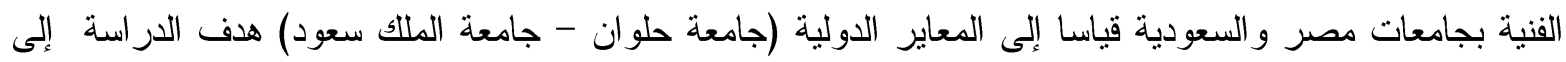
التعرف على الجودة الأكاديمية، وعلى طر ائق تحقيقها في مادة التربية الفنية، وبرامجها التي تقدم في أقسام التربية الفنية بالجامعات، وبكليات التربية الفنية في المملكة العربية السعودية وجمهورية مصر العربية، وقد استخدم الباحث، المنهج الاستقرائي، وذللك لمر اجعة أدبيات الدر اسة بهدف التعرف على مساهمات الباحثين الذين كتبو ا في هذا المجال، والاستفادة من بعض الممارسات أو التجارب العملية السابقة، اضافة إلى المنهج الاستنباطي لدراسة مدى إمكانية 
تحقيق الجودة و الاعتماد في مجال التربية الفنية. توصلت الدراسة أن مناهج التربية الفنية في الجامعات العربية عامة، وفي جامعات وكليات المملكة العربية السعودية في حاجة ماسة للتجديد لتحقيق الجودة و الاعتماد و التميز • وقد سبقتنا بعض الدول الآسيوية مثل ماليزيا، إضافة إلى عدد كبير من الدول الغربية في هذا المجال. وقد قدم الذين سبقونا نماذج يمكن الاستفادة منها. وبناء على ما سبق فإن الباحث يوصي بإعادة صياغة مفردات ومقررات التربية الفنية بالجامعات والكليات السعودية حتى تو اكب المستجدات العالمية وتحظى بالاعتماد وتحقيق التميز، و استحداث برامج جديدة ومواد إضافية بمناهج التربية الفنية حتى تتيح للخريج فرصاً أوسع للعمل بجانب توسيع مداركه الفنية و الأكاديمية والاجتماعية، و إثراك قطواتيات مختلفة من المجتمع في الأنشطة الأكاديمية، و التشاور معهم عند ثقويم

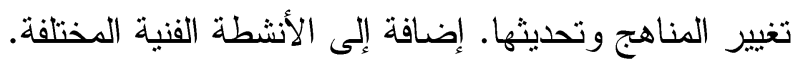
. دراسة المعدر (9 . . ب) بعنوان: النظم الزخرفية في العمارة النجدية كمصدر لتصميم اللوحة الزخرفية، هدفت الدراسة الى إلقاء الضوء على طبيعة منطقة نجد و العو امل الجغرافية والمناخية التي أدت إلى ظهور طراز

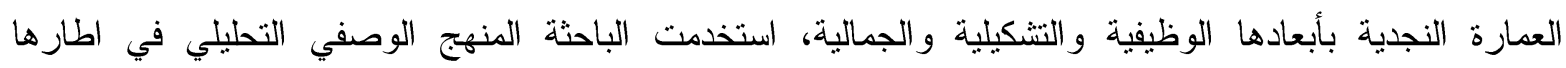
النظري، والمنهج التطبيقي لتحديد نظم انتاج اللوحة الزخرفية تزاثية الطابع. بالإضافة إلى دراسة وتحليل النظم الزخرفية في العمارة النجدية لكي يسهل التعرف على عناصرها ومكوناتها وأبعادها التثكيلية وأسس بنائها، وأيضاً

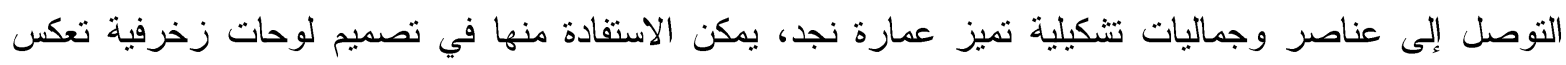
الهوية السعودية، انتهت الدراسة الى مجموعة من اللوحات الزخرفية قائمة على المنهج التجريبي، باستنمار العناصر و النظم الزخرفية في العمارة النجدية، وتوظيفها نتكيلياً في ضوء المفهوم المعاصر للوحة الزخرفية. وكان من اهم

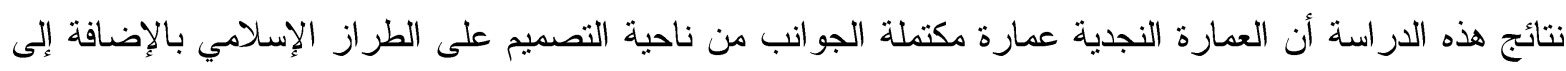
ملاءمة طبيعة المو اد المستخدمة في البناء للمناخ.

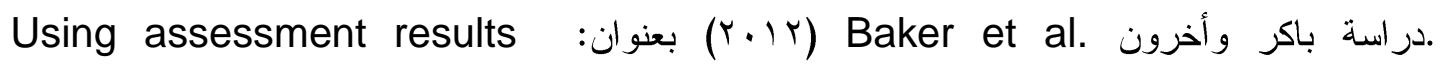
Promising practices of institutions that do well

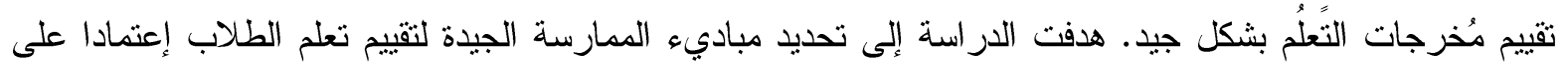
استخدام استز اتيجيات التقييم ومردود ذلك على العملية التعليمية، من خلال عرض نتائج المعهد الوطني لقياس وتقييم

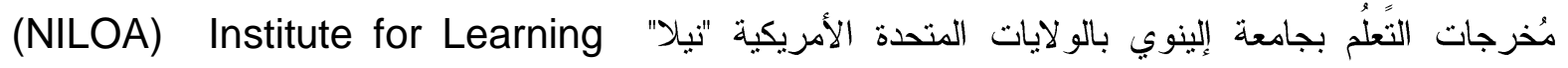
Outcomes Assessment

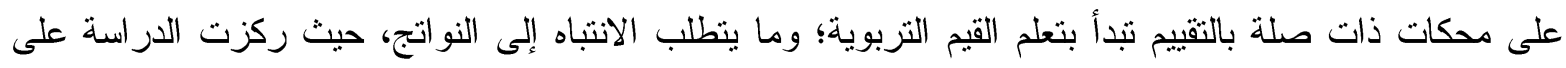
استخدام أدلة تعلم الطالب التى تستخدمها المؤسسات التعليمية لتحسين مستوى الاداء من خلال: تحديد الأولويات

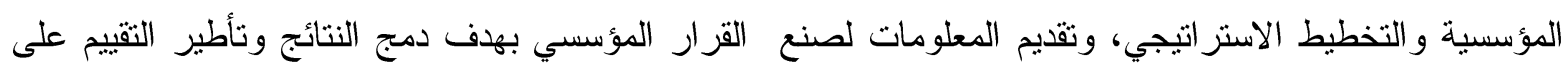
مستوى المؤسسة، ومر اجعة نواتج تعلم المؤسسة ضمن جهود الاعتماد والجودة، وتحسين مشاركة الطلاب ونجاحهم. وقد توصلت دراسة باكر للعوامل المشتركة في دراسة الحالة التي أجريت على الجامعات التي لديها الرغبة في

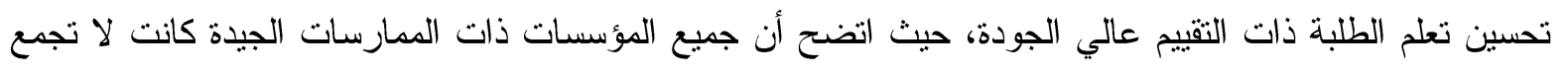
البيانات و الأدلة فقط، بل تستخدم نتائج تقييم الطلبة لتحسين إستر اتيجيات التعلم، وتقوم بدر اسة ناقدة للعمليات المؤسسية وممارسات الفصول الدراسية إلى جانب الأنشطة اللاصفية. اشارت نتائج الدراسة إلى أن التقييم يعمل بشكل أفضل 
عندما تكون البر امج التي يسعى لتحسينها ذات أغر اض و اضحة، وان التقييم يكون أفضل عندما يكون مستمر اً، و أكثر فعالية عندما يُنظر للعملية التعليمية على أنها متعددة الأبعاد، ومتكاملة، ويظهر من خلالها تحسن الأداء مع مرور الوقت داخل المؤسسات الاكاديمية. لدر اسة الهيئة الوطنية للتقويم والاعتماد الاكاديمي، وحدة الجودة والاعتماد الاكاديمي بجامعة الملك سعود (9 . . r) بعنوان: معايير ضمان الجودة والاعتماد لمؤسسات التعليم العالي. هدفت الدراسة إلى وضع إستر اتيجيات

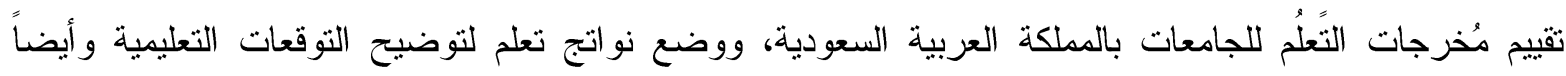

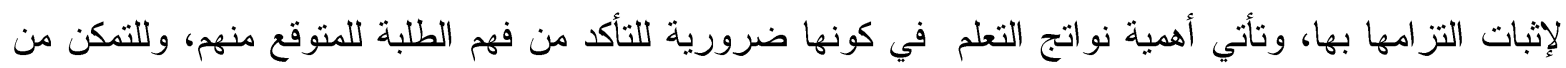

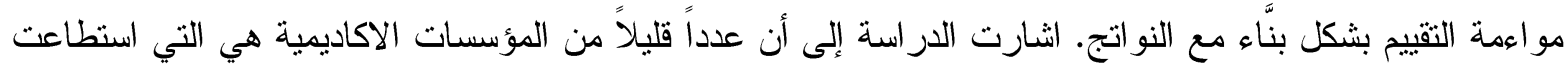
أن تجري تقيماً لتعلم الطلاب بحيث يكون منظماً وشاملاً لجميع المستويات بالمؤسسة وبالشكل المطلوب، و وأن تستخدم

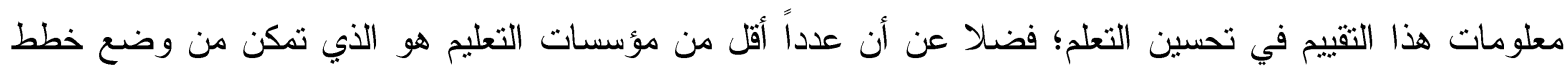

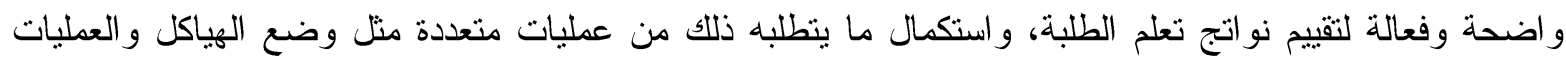

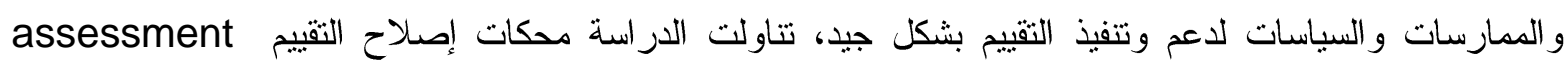
reform trials، قادتها هيئات الاعتماد، حيث طالبت الجامعات و الكليات بالاهتمام بشكل كبير بالتدريس و التعلم الذي تهي

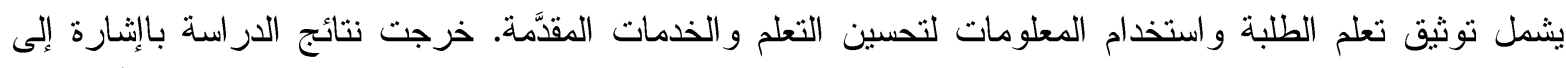
زيادة نوقعات الاعتماد و المساءلة الخارجية، بحيث أصبحت المؤسسات التعليمية مطالبة بتحديد مُخرجات التُعلمُ الطلبة

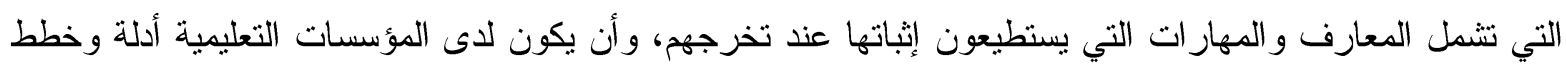
و اضحة لتقييم تعلم الطلبة، وما نم عمله فيما يتعلق بأدلة تقييم نواتج تعلمهم، واستخدام تلك الأدلة لتحسين تعلم الطلاب.

\section{الإطار الأول: جماليات النظم الزخرفية للأبواب الشعبية في المملكة العربية السعودية:} يمثل التذوق الفني و إكتشاف الخصائص الجمالية للأعمال التزاثية إستجابة المتذوق إلى ما أضفاه الفنان من فن فئه

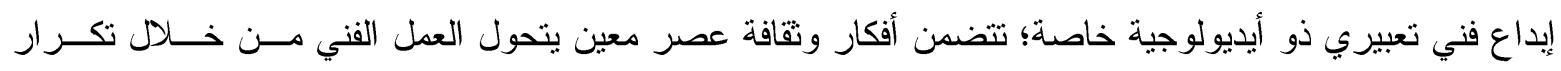
وتركيب المتذوق للعملية الإبداعية التي قام بها الفنان إلى مضمون ومحتوى فني، وما يتضمنه مسـن نظــام ونسـق

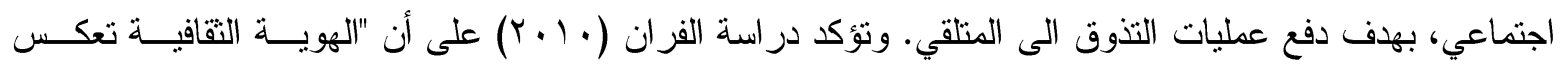
الخصائص البيئية والاجتماعية للمجتمعات، مشير ا إلى ما تحمله المفردات التزر اثثية ما يعكـس جماليــات المـــوروث

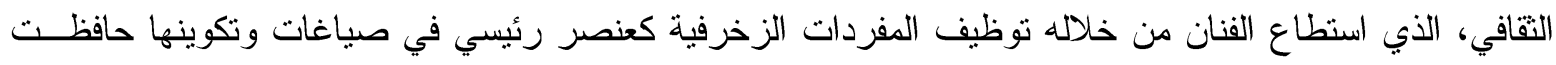

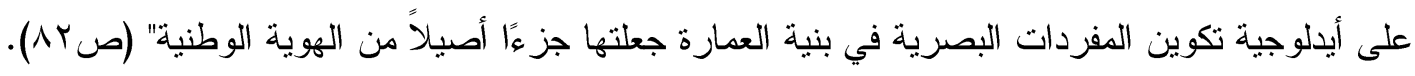

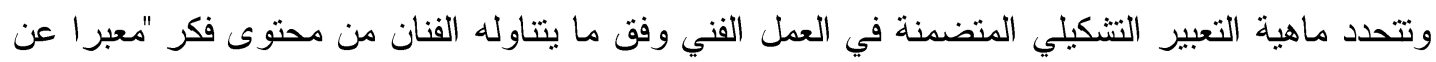
الاتجاهات الاجتماعية التي تعبر عن ثقافة المجتمع، وتميز بها عصره، ممثلة في المضمون الأيديولوجي الذي يصنف

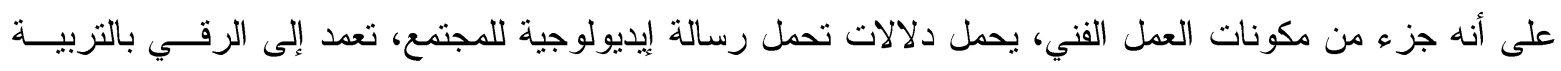

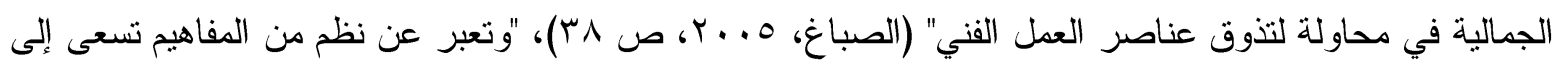

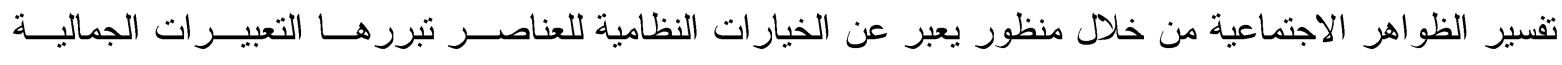


للتشكيلات الفنية المتمازجة مع فلسفة الفكر الجمالي لذلك المجتمع" (أنور، ـ ا ـ Y، ص VY). فالأيديولوجيا الجماليــة

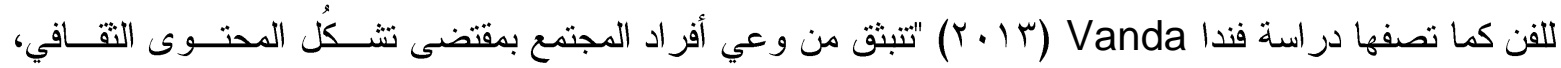
وتتمثل نتيجة للممارسات اليومية لصياغات العلاقات الاجتماعية، و التقافية، المختلفة للتعبير عـن التقافــة الجماليــة للمجتمع معبرة عن تكر ار لمفردات فنية" (صسی). فالمفردات الزخرفية ومكملات العمارة مجال تسهم في تحدد هوية المجتمعات و انتمائها وتاريخها، فالابو اب الخشبية عبارة عن تشكيل وظيفي إلى جانب كونها تشكيل اجتماعي يـؤدي منطلبات حياتية بوسائل مادية بارتباط وثيق بطبيعة المجتمع وزمانه، فإنها تخضع للمؤثرات الاجتماعية والاقتصادية إضافة إلى خضو عها لعو امل متعددة نشكل طر از ما بها من زخارف" (Othman, 2011,p81). فالأبو اب تكون من خشب الأتل لقوته ومقاومته للظروف المناخية، يقوم الحرفيون بزخرفتها وتلوينها ويكون لها (مجرى) لفتحها و إقفالها وعادة ما يكون من (الداخل) ومن يريد فتح الباب يدخل يده من (الكوّه) ويفتحه، و الكوّه عبارة عن فتحة صغيرة بجانب الباب تكفي لدخول اليد. وبعض الأبو اب الكبيرة تكون من جذوع النخل بعد تسطيحها

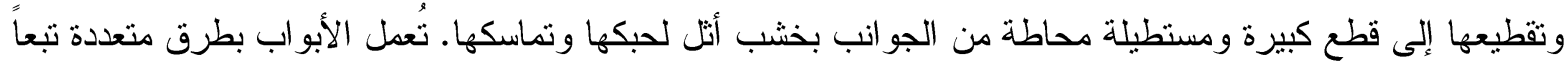
لأهمية كل نوع و الوظيفة المستعمل من أجلها، فالأبو اب الرئيسية تختلف عن أبواب الحجرات الداخلية و أبو اب دورات المياه و المخازن و غيرها، وتكون عناصر الزخرفة و النقوش على الأبو اب بأثكال هندسية مكونة من خطوط ومساحات

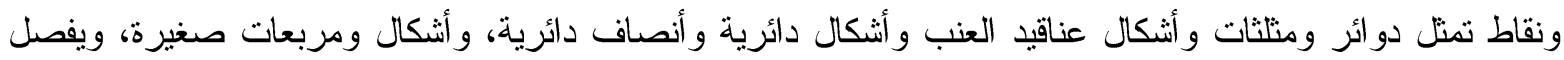
بين هذه الأشكال خطوط تأخذ في الغالب اللون الأخضر و الأحمر، وبأصباغ محلية أو بالحرق. ولتذوق جماليات النظم الزخرفية للابو اب الخشبية سعودية الطابع مجموعة من الأبعاد التي تساهم في مقدرا

المتعة الجمالية التي يصل إليها المتذوق للزخارف التزاثية وهي: ـ البعد الوجداني لعملية التذوق: القيم الثخصية و الاتجاهات و الميول و الدو افع و الخصائص الثخصية. فهو نمط مركب من السلوك يتطلب في جوهره إصدار أحكام على قيمة شيء. ـ البعد التذوقي الاجتماعي و التقافي لعملية التذوق: يتضمن التراث الثقافي والاقتصادي. فالتذوق الفني كعملية لا تتم على مستوى واحد بل تأتي على مستويات متفاوتة نتيجة تقافة المتذوقين وحالتهم المزاجية و النفسية والاجتماعية و البيئية. .البعد الجمالي التشكيلي لعملية التذوق: الخصائص الجمالية الكامنة عند المتلقي وفي مكونات العمل الفني، أو الفكرة أو الموضوع من الناحية الجمالية.

\section{الإطار الثاني: معايير الجودة الشاملة لتعليم تذوق الفنون البصرية في المملكة العربية السعودية وفق وثيقة الإطار}

أصبح تقييم وقياس مُخرجات التَّلُم جزءاً من عملية الاعتماد الأكاديمي والمؤسسي لدى معايير الهيئة الوطنية للتقويم والاعتماد بالمملكة العربية السعودية، ومن المتطلبات الأساسية لدى معايير ضمان الجودة، حيث تتطلب تحديد نو اتج التعلم المتوقعة، وتقييم مدى تحققها، وتقديم الأدلة على التحسن من خلال تحليل النتائج في كل منها

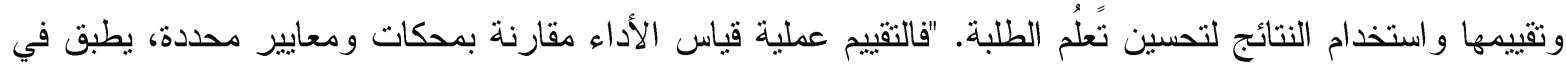
سياقين الأولى مرتبط بتقييم أداء الطلاب في الاختبار ات أو الامتحانات أو غيرها ها من المهام لقياس تحقيق نواتج التعلم 
المستهدفة؛ والثاني مرتبط بقياس جودة أداء عناصر التُعلُم داخل إطار المؤسسة التعليمية" (الهيئة الوطنية للإعتماد، . (r) מ

هذا ويعد التعليم وفق وثثقة الإطار التخصصي من المصطلحات التي تصف ممارسة التدريس من أجل

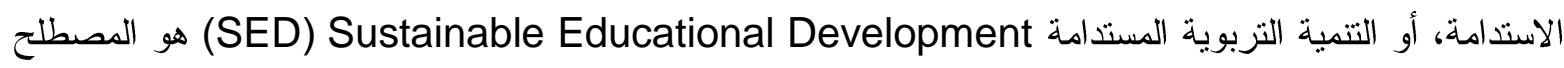
الأكثر استخدامًا، حيث أقرت منظمة اليونسكو وثثية دولية حددت التعليم كأداة أساسية لتحقيق التتمية المستدامة وسلطت الضوء على مجالات التعليم بوصفها وسيطاً للتنمية المجتمعية. و المفهوم التشكيلي لتتمية التذوق الفني بصورة مستدامة قائم على دعم معرفي للتقافة ينطوي على نظرة شاملة لبيئة التعلم، تعمل على التحول من التلقي، إلى تكثيف استر اتيجيات صناعة المعرفة التشكيلية، بمعنى أنه لا يمكن تفعيل الاستدامة بمعزل عن التوجهات الاكاديمية وفق أبعاد

فقد نوصلت الدراسات المعاصرة إلى أن التعليم وفق وثيقة الإطار التخصصي هو أسلوب حياة تحكمه أُطر تربوية، إلى جانب أنها نمط تتموي يسعى إلى بناء مجتمع أقل ميلاً للنزعة الاستهلاكية و استبداله بمبدأ الأكثر استدامة.

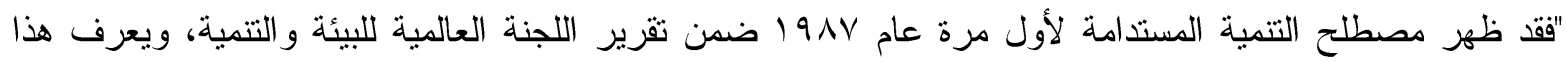
بتقريز برونتلاند Brundtland نسبة إلى برنامج الأمم المتحدة الإنمائي حول مفهوم التنمية التي تضع الإنسان في أولوية أهدافها وهو ما تُصنع التتمية من أجله، على اعتبار أن التتمية تهدف إلى الاستثمار في قدرات البشر ، سو اء في

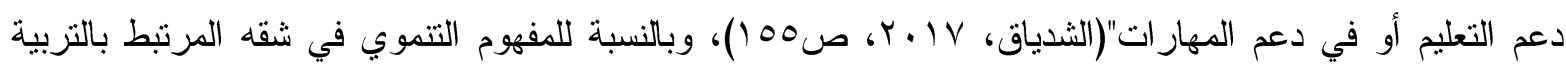
الفنية و الفنون، فالاستدامة تعني مفهوماً يتتاول بالدراسة و التحليل العلاقة بين أنواع وخصائص المكونات الاساسية

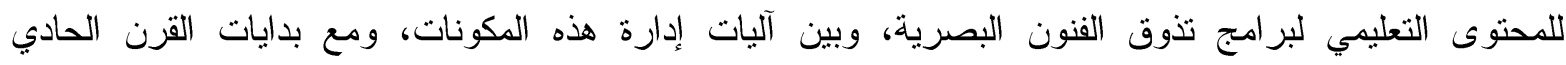

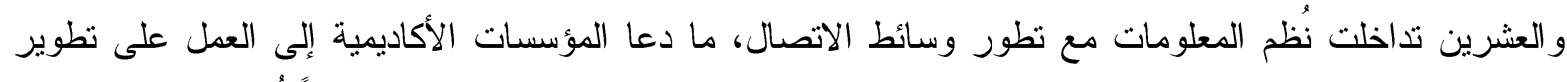

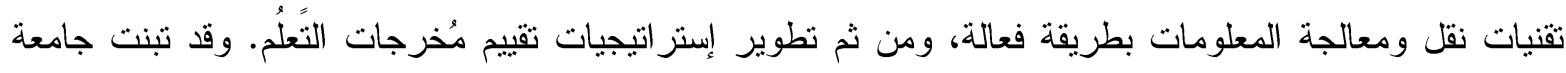
الملك سعود مبادئ ذات ارتباط مباشر بالتتمية التشكيلية المستدامة لتصبح المعرفة وتطبيقاتها الفنية أبرز مظاهرها بهدف تعزيز مفاهيم جديدة للاستدامة مثل "مجتمع المعلومات" أو "مجتمع المعرفة" مع التحول الذي تشهده رؤية المملكة • ـ • ب لتوسيع المجالات و الإمكانيات و المهار ات وفرص التتمية، وقد ورد ضمن أهداف عمادة البحث العلمي

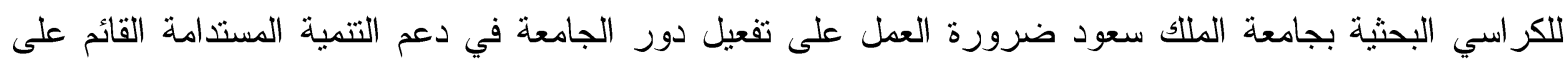
المعرفة، علي إعنبار أن المعرفة هي جوهر التنمية، لذلك أضيف مفهوم التنمية المستدامة إلى مفاهيم التزبية الفنية ليصبح مفهوم التنمية التشكيلية المستدامة في ضوء مجتمع المعرفة. ولتعزيز مفاهيم التنمية المستدامة القائمة على هلى مُخرجات برامج الفنون البصرية؛ "طرح مؤتمر اليونسكو للتعليم من أجل التتمية المستدامة إعلان أيتشي ناجويا Aichi-Nagoya الفنية و الفنون البصرية في التعليم و التدريب التنمية المستدامة، و إعادة توجيه التعليم والتعلم بحيث تتاح للطالب فرصية

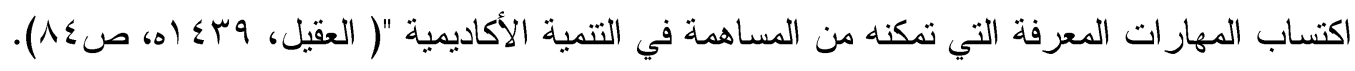
مما سبق يتبين أن المفهوم التشكيلي للتنمية المستدامة هو نهج دراسي وأسلوب تلقي معرفي تمثلك برامج التربية الفنية ككل، وفلسفة تربوية تقوم على التفكير بطريقة تكاملية من خلال تقييم مخرجات نُظم التعلم الكلية و الفرعية، وما يربطها من علاقات وتفاعلات وما يترتب عليها من نتائج وعمليات تغذية راجعة في التعامل مع 
مشكلات تذوق الفن التشكيلي بشكل فعَّل. وتجدر الإشارة إلى ان الإطار التخصصي لمجال تعلم التزبية الفنية المعتمد من هيئة تقويم التعليم تتضمن وثيقة تحدد مجال التربية الفنية، ووصفاً لطبيعته، والتوجهات العامة في تعلمه، التهات ومسوغات تضمينه كمجال تعلم في التعليم العام، و الأهداف العامة لتعلمه، كما تحنوي على وصف لبنيته كمجال تعلم، من خلال تسمية فروعه، وتحديد الأوزان النسبية له، والأفكار المحورية والمفاهيم الرئيسة لكل فكرة محورية في

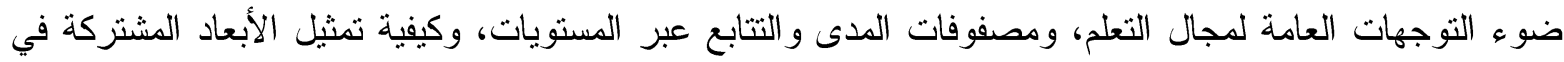
المعايير، وتطبيق المبادئ التوجيهية، وتوضيح كيفية بناء معايير التربية الفنية التى اقرت ضرورة تضمين

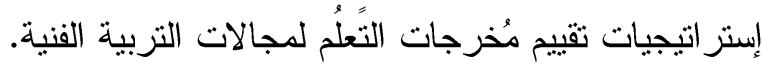
منهج البحث واجر اع|ته: (أ) منهجية البحث: اتبع البحث المنهج الوصفي التحليلي؛ "والذي يركز على وصف الأبعاد التشكيلية والجمالية لجماليات النظم الزخرفية للأبو اب الثعبية في المملكة العربية السعودية في ضوء معايير الإطار التخصصي، وكي، ومن ثم

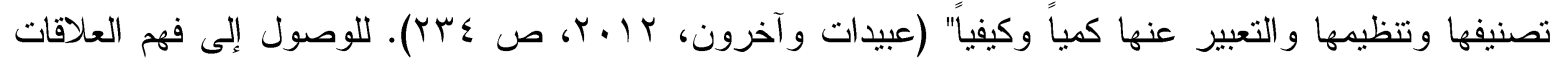
الفكرية و الفلسفية و التقافية والاجتماعية و الدينية للوصول إلى استتاجات وتعميمات تساهم في تطوير مستوى التذوق

عينة البحث المادية: مختار ات من الأبو اب الثعبية تمثل مناطق المملكة (المنطقة الوسطى، المنطقة الشرقية، المنطقة

الغربية، المنطقة الجنوبية). عينة البحث البثرية: إستعان الباحث برواد جمعية الثقافة والفنون (المركز الرئيسى بالرياض) بهدف قياس تاثير

$$
\text { برنامج التذوق الفني المقترح (قبلي • بعدي). }
$$

(ت) أداة البحث: قام الباحث بإعداد استتبانة النظم الزخرفية لبندية للأبو اب الثعبية في المملكة العربية السعودية في ضوء معايير الإطار التخصصي حسب مناطق المملكة الأربعة، وستشمل الاسنبانة على المحاور التالية: - - المحور الأول: جماليات النظم الزخرفية للأبواب الثعبية في المملكة العربية السعودية. - - المحور الثاني: معايير التذوق الفني المتضمنة في الإطار التخصصي لمجال التزبية الفنية والفنون في المملكة. - المحور الثالث: مواصفات البرنامج المقترح للتنوق الفني قائم على جماليات النظم الزخرفية للأبواب الثعبية في المملكة العربية السعودية في ضوء معايير الإطار التخصصي. - وتم إستخدام مقياس ليكرت الرباعي في قياس استجابات العينة تجاه محاور الاستبانة:

\begin{tabular}{|c|c|c|c|c|}
\hline لا يوجد & بلرجة متوسطة & بلرجة عالية & بلرجة عالية جداً & بنود المحور \\
\hline 1 & $r$ & r & $\varepsilon$ & تو افر تحقق بنود المحور \\
\hline
\end{tabular}

(ث) الأساليب الإحصائية المستخدمة في البحث:

$$
\begin{aligned}
& \text { (1) المتوسطات الحسابية، و الإنحر افات المعيارية، و التكر ارات و النسب المئوية. } \\
& \text { (Y) معامل ارتباط بيرسون لاستخر اج الاتساق الداخلي. } \\
& \text { (r) معامل ألفا كرونباخ لقياس ثبات الأداء على الاستبانة. }
\end{aligned}
$$


(§) اختبار T-test لعينتين مستقلتين لاختبار الفروق بين منوسطات الاختبار البعدي للمجموعتن التجريبية و الضابطة. (0) اختبار T-test لعينتين مترابطتين لاختبار الفروق بين متوسطات الاختبار البعدي للمجموعتن التجريبية و الضابطة. نتائج البحث ومناقشتها: الاجابة عن السؤال الأول الأي ينص على: ما جماليات النظم الزخرفية للأبواب الثعبية في المملكة العربية

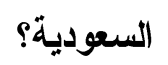
تتميز العمارة السعودية التزاثية بجمال أبو ابها ونو افذها من خلال ما ينم تزيينها به من زخرفة تتصف بالبساطة والجمال و الاعتماد على البيئة المحلية؛ ما يعمل على تأصيل الهوية العربية فالنظم الزخرفية على لئى الأبواب

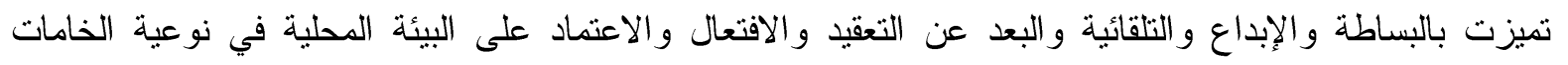

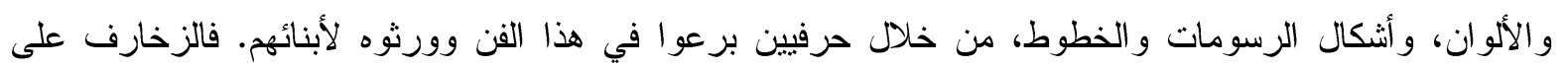

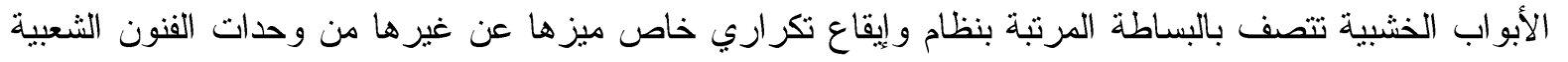

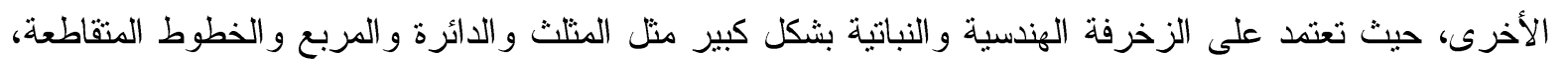

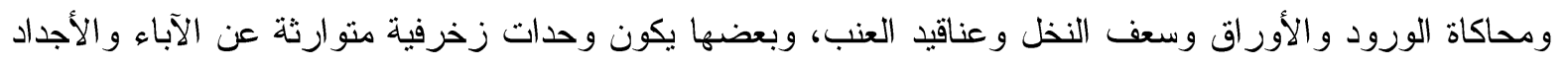

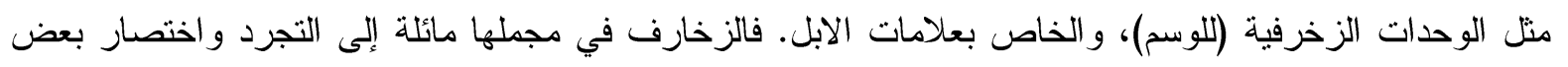

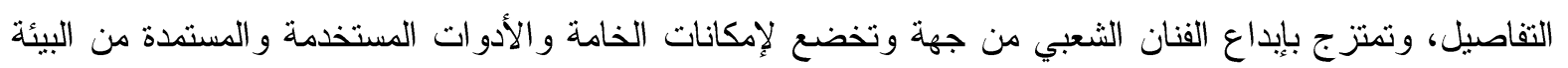

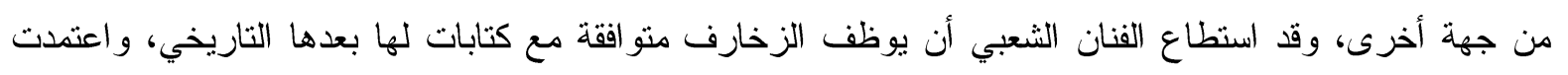
الزخارف على الخطوط و الثشكيلات الهندسية في تكوينات جمالية لها دلالاتها الثكلية.
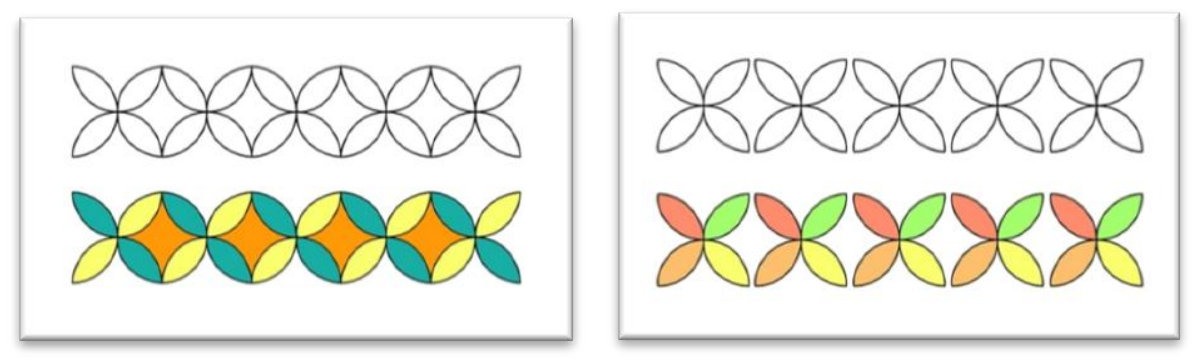

الاجابة عن السؤال الثاني الذي ينص على: ما اهم معايير التذوق الفني المتضمنة في الإطار التخصصي لمجال التربية الفنية والفنون في الملكة العربية السعودية؟ التئه تعتمد بنية مجال التربية الفنية في المملكة العربية السعودية على العنصرين التاليين:

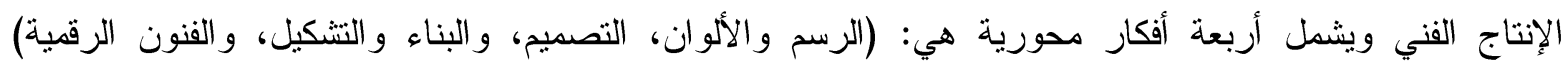

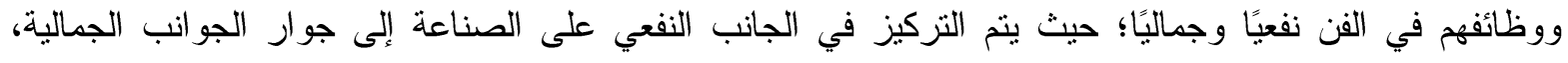

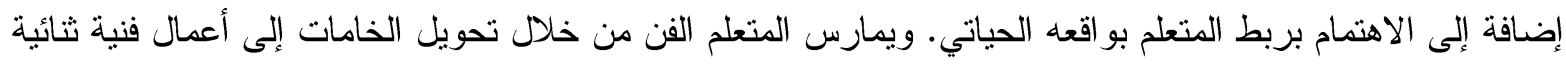

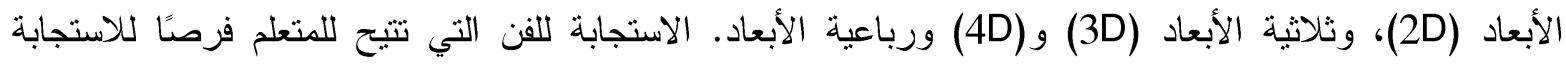

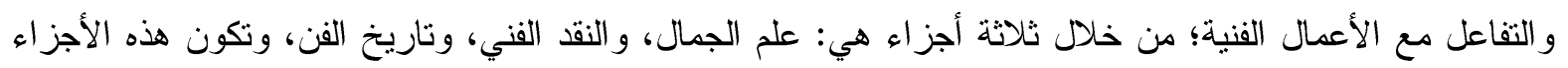

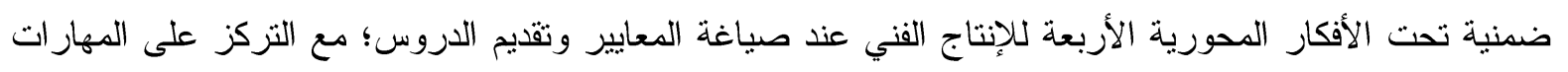


المشتركة مثل التفكير الناقد، والتفكير الابداعي، و التو اصل، و التعلم الذاتي، والتعلم التعاوني، مهارات العمل التعاوني.

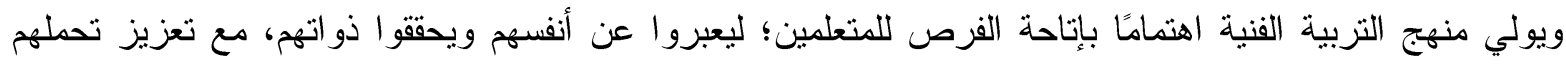

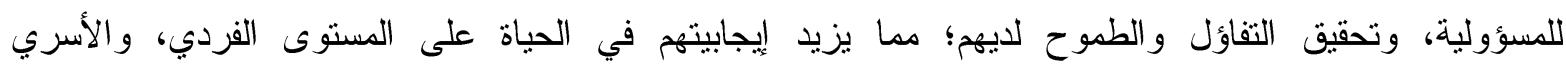

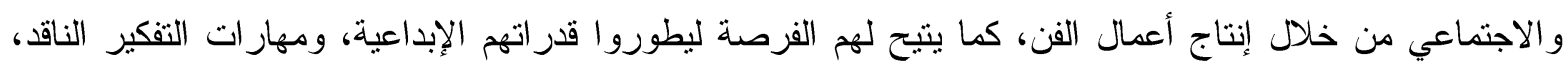

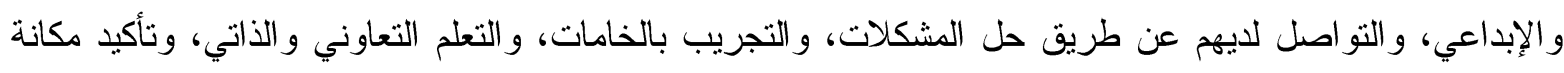

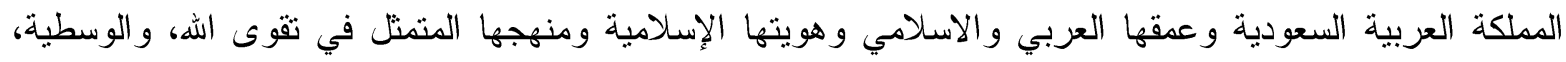

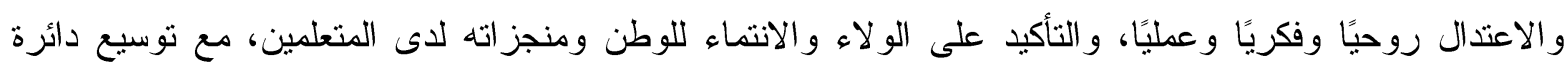

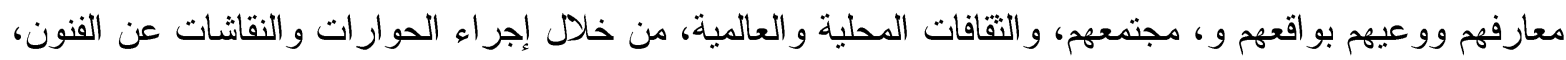

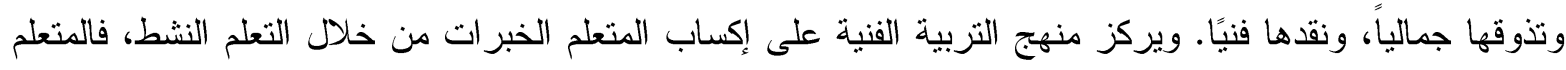

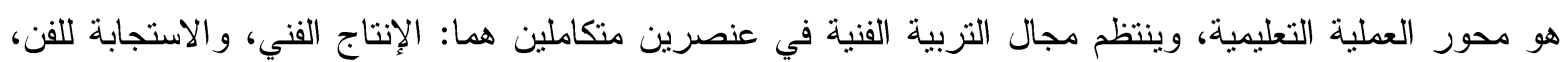

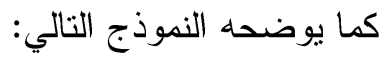

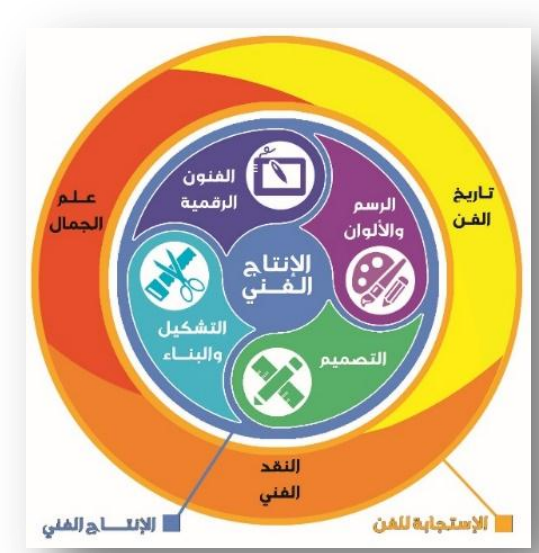

عن: كيئة تقويم التعليم r.IV

الاجابة عن السؤال الثالث الذي ينص على: ما إمكاتية إعداد برنامج مقترح للتذوق الفني قائم على جماليات النظط

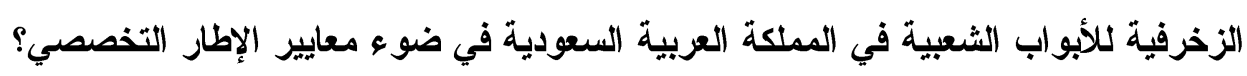

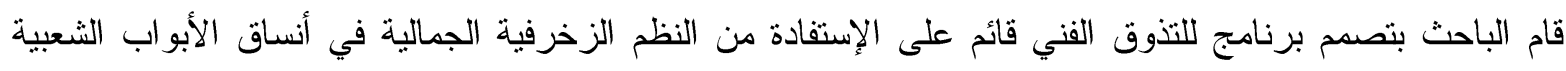

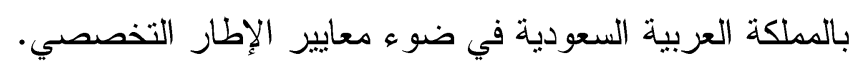

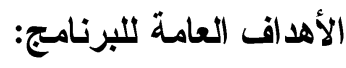

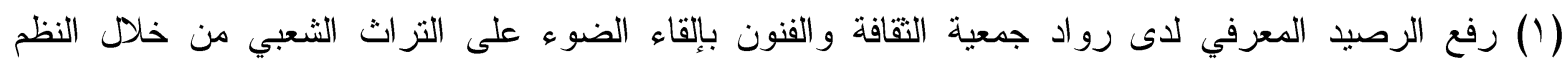
الزخرفية الجمالية في أنساق الأبو اب الثعبية للعمارة الثعبية.

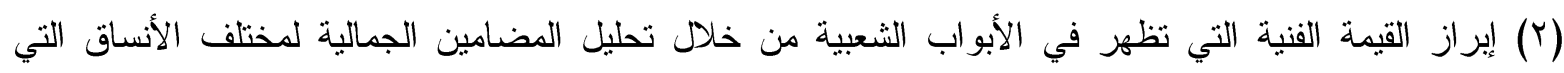
تضمنتها الأبو اب في مناطق مختلفة بالمملكة العربية السعودية. 
(r) التعرف على معايير التذوق الفني المتضمنة في الإطار التخصصي لهجال التربية الفنية والفنون وتتاولها للموروث في المملكة العربية السعودية

(؛) توسيع دائرة معارف المتلقي ووعيه بتز اثه ومجتمعه، والثقافات المحلية والعالمية، من خلال إجراء الحوارات و النقاشات عن الفنون، وتذوقها جمالياً، ونقدها فنيًا.

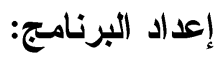

(1) إعتمد الباحث على أدبيات العلمية لتحديد الأسس النظرية للبرنامج و التي تتناول متغيرات البحث، وتساعد في بناء البرنامج بأسلوب علمي بالطرق و الوسائل المناسبة لتطبيقه.

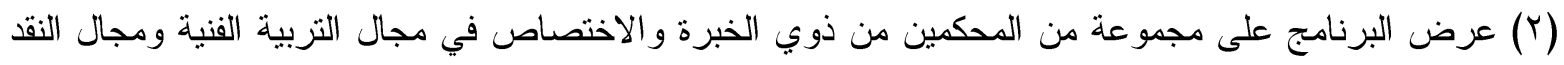

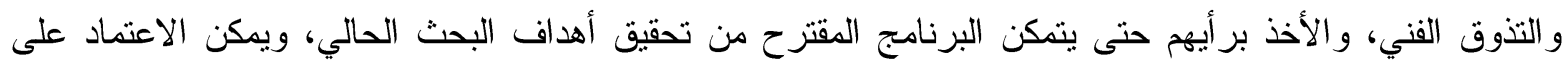
نتائجه. (ب) تم تحديد تفاصيل الخطة الزمنية للبرنامج من حيث المكان، والمدة الزمنية، وعدد المحاضرات، وأهداف كل محاضرة والأساليب و النقنيات المختلفة في تطبيقه.

(§) عمل دراسة استطلاعية للبرنامج المقترح على عينة من مجتمع البحث، للتعرف على صلاحية البرنامج المقترح

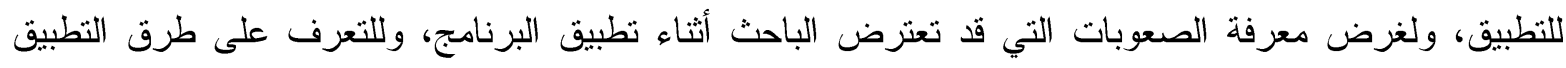

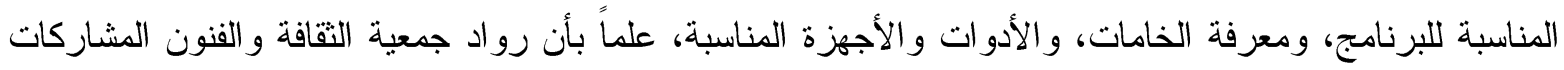
في التجربة الاسنطلاعية سوف يتم استبعادهم لكي لا تتأثر نتائج البحث.

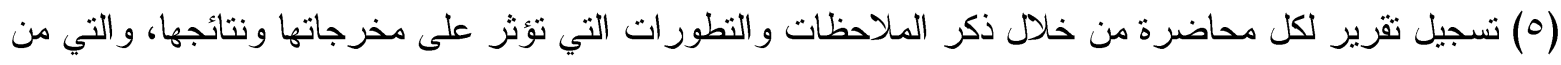
شأنها توجيه وتعديل برنامج التذوق الفني الكقترح. 


\section{النتائج التطبيقية للبحث:}

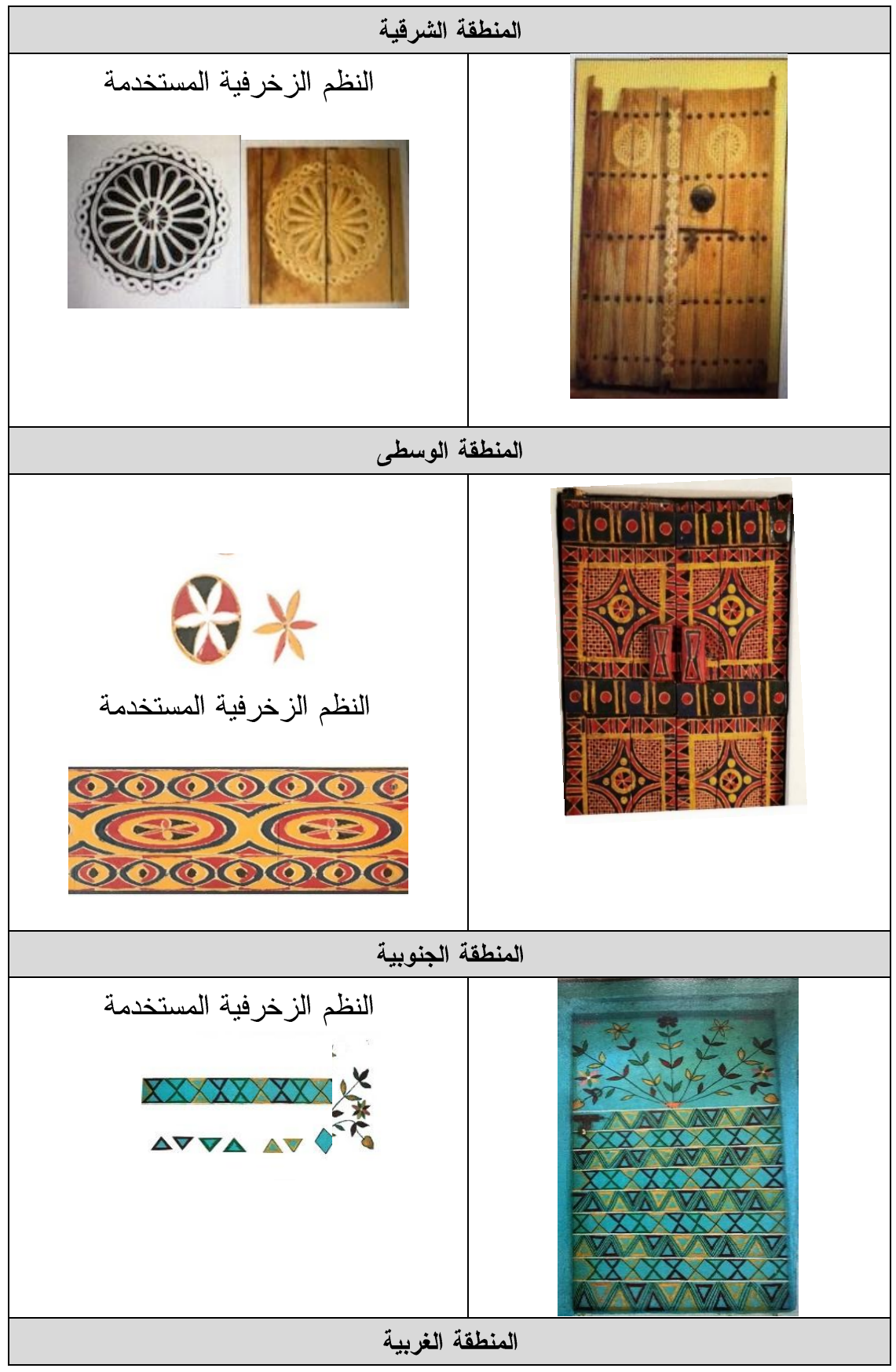




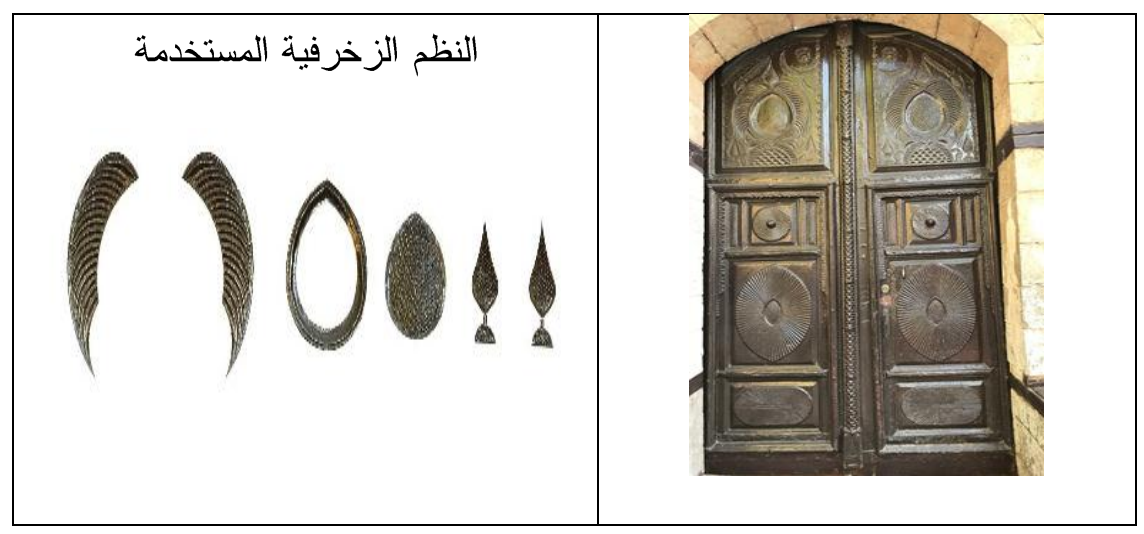

نتائج وتوصيات البحث: اولاً: النتائج:

التعرف على جماليات النظم الزخرفية للأبو اب الثعبية في المملكة العربية السعودية.

(Y) تحديد اهم معايير التذوق الفني المتضمنة في الإطار التخصصي لمجال التربية الفنية والفنون في التعليم العام في المملكة العربية السعودية.

(r) إعداد برنامج مقتزح للتذوق الفني قائم على جماليات النظم الزخرفية للأبواب الشعبية في المملكة العربية السعودية في ضوء معايير الإطار التخصصي.

(ع) إبراز القيمة الفنية التي تظهر في الأبواب الثعبية من خلال تحليل المضامين الجمالية لمختلف الأنساق التي تضمنتها الأبواب في المناطق الجغر افية بالمملكة العربية السعودية. (0) التعرف على معايير التذوق الفني المتضمنة في الإطار التخصصي لمجال التربية الفنية والفنون وتتاولها للموروث في المملكة العربية السعودية ثانياً: التوصيات: (1) وضع قائمة معايير خاصة بتصميم و إنتاج المقررات الإكترونية لمقررات التربية الفنية للتذوق التراثي في المملكة العربية السعودية في ضوء الجودة الثاملة. (r) يمكن أن تسهم نتائج البحث الحالي في مساعدة صنّاع القرار بوزارة التعليم على التعرف إلى واقع مقررات التزبية الفنية الحالية في المملة العربية السعودية. (r) استكمال الدر اسات برؤية و اضحة بأنو اع الزخارف الثعبية في العمارة التقليدية، واسمائها، و التعرف على طرق تصنيفها، وتحليلها، وسماتها، وخصائصها الفنية وقيمها الجمالية. (§) إستكمال الدر اسات بالتعرف على التقنيات، و الأساليب الفنية المستخدمة و الإفادة منها في تحقيق قيم فنية وتشكيلية لمفردات ترتثية بشكل معاصر وطرح حلول تصميمية جديدة. (أن يحتوي الإطار التخصصي على مداخل استلهام مفردات التزاث بشكل اكثر حداثة. 


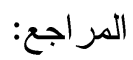

معالم التزاث العمر اني في المملكة العربية السعودية (• ( ب). الهيئة العامة للسياحة والآثار: مكتبة الملك فهد الوطنية.

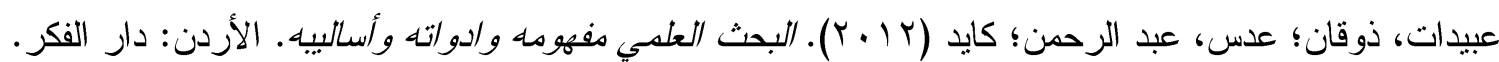

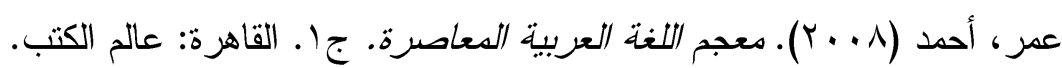
خطابي، صالح (•rع اه). الاعدال الخشبية في العدارة التقليبية بهنطقة العدينة الهنورة. رسالة دكتور اه. جامعة الملك

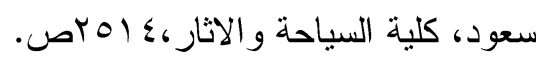

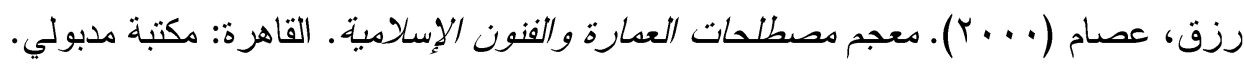
الو ايل، سعيد (اسع اه). الابواب والنقوش الخشبية التقليدية في عمارة المنطقة الثرقية بالمدلكة العربية السعودية. الرياض: دارة الملك عبد العزيز.

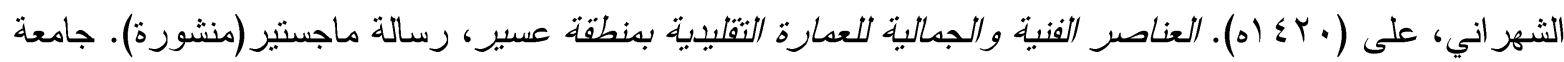

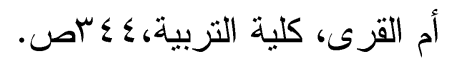

التويجري، عبد العزيز (11 (r). التزاث والهوية. منشورات المنظمة الإسلامية للتربية و العلوم الثقافية، إيسيسكو: الرباط.

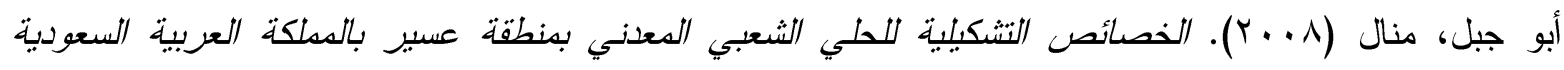
كمصدر لصياغات حديثة للحلي. رسالة ماجستير (غير منشورة). جامعة حلوان كلية التزبية الفنية.

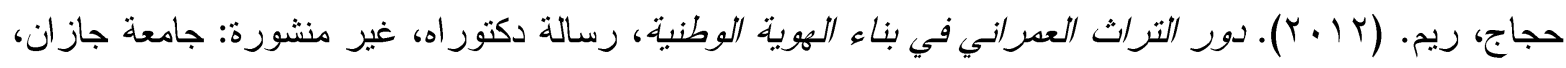
كلية العمارة و التخطيط.

نور، مي عبد المنعم (9 99 ()) تصميم منهج التزبية الفنية للمرحلة الثانوية في ضوء اتجاهات معاصر للتربية الفنية، رسالة ماجستير، كلية التربية الفنية، جامعة حلوان، القاهرة.

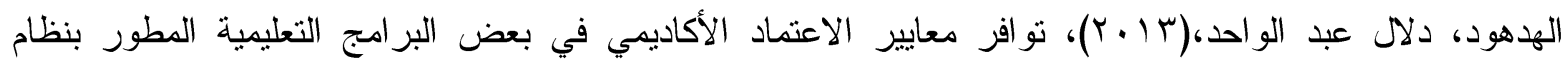
الويدز WIDS بكلية التربية الأساسية في ضوء بوار بعض المتغيرات : دراسة ميدانية تحليلية، مجلة كلية التربية

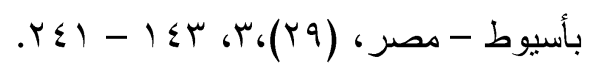

العجيل، محمد ناصر (؟ ( r) تطوير برنامج تدريب معلم التربية الفنية بدولة الكويت في ضوء معايير الجودة

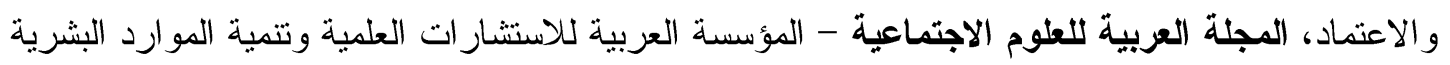

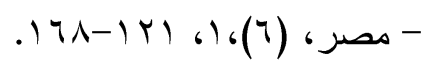

الصاعدى، عبير (•(ب) التوصل الحضاري للطرز المعمارية الاسلامية على واجهات المباني التقليدية في مكة المكرمة و الافادة منها في تصميم واجهات المباني المعاصرة. رسالة دكتور اه غير منشورة، جدة: جامعة

$$
\text { الملك عبد العزيز . }
$$

المعمر ، سلطانة. (9 . . r). النظم الزخرفية في العدارة النجدية كمصدر لتصديم اللوحة الزخرفية، رسالة مقدمة لنيل درجة الماجستير، جامعة الملك عبد العزيز، كلية التربية للاقتصاد المنزلي و التربية الفنية بجدة. الزهر اني، عبد الرحمن. (10 • (1). إطار التراث العدراني، الرياض: مركز البحوث و الدراسات الأثرية. 


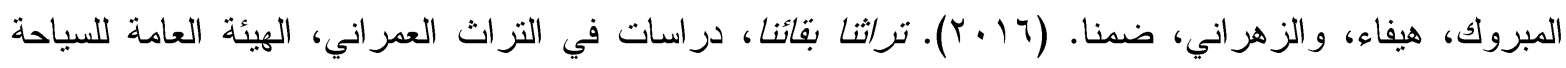
و الآثار .

Anna Haratyk (2017). Folk Art and Culture in the Historical and Educational Context.Czech-Polish: Historical and Pedagogical Journal.

Babelli, Mohammed, Alqwuiee, Mohammed, Greenberg, Elisabeth (2011). Jandria Saudi Heritage.Riyadh: Desert Publisher.

Herbert Read (1961). The Meaning of Art.Britain: Richard Clay\&Company, Ltd, Bungay, Suffolk. John, Kevin (2003) Blobitecture, Waveform Architecture and Digital Design, USA: Rockport.

Ross Jhon, Romano Clare (1974). The Complete new Thchniques in Print mking, New York: Free Press.

Longman, Dictionary of Contemporary English 6th Edition (2018). London, Uk: Pearson.

$\mathrm{R}$, Othman (2011). The Importance of Islamic Art in Mosque, Integrin Intelligent press. New York.

Vanda Ingalls, D. (2013) Developing dynamic artist/teacher/leaders in preservice art education programs. In D. Flinders \& P.B. Urlacher (Eds.), Curriculum and Teaching Dialogue, Volume 15 (pp. 101-116). Charlotte, NC: Information Age Publishing. 